Article

\title{
Study on Design Strategy for Sustainable Development of Chinese Solar Term Culture
}

\author{
Wen-Tao $\mathrm{Li}^{1, *}$, Ming-Chyuan $\mathrm{Ho}^{2}$ and Chun Yang ${ }^{1}[$ \\ 1 Graduate School of Design, National Yunlin University of Science \& Technology, Yunlin 640, Taiwan; \\ yc004009@gmail.com \\ 2 College of Design, National Yunlin University of Science \& Technology, Yunlin 640, Taiwan; \\ homc@yuntech.edu.tw \\ * Correspondence: D10530023@yuntech.edu.tw; Tel.: +886-96-6640-322
}

Received: 13 October 2018; Accepted: 6 November 2018; Published: 22 November 2018

\begin{abstract}
The 24 solar terms that form the traditional lunisolar calendar were created by ancient Chinese people. Through a literature review and semistructured interviews, this study clarified 19 key items of the design strategies for the sustainable development of solar term culture, and conducted factor extraction through factor analysis using SPSS statistical software on four types of expert questionnaires, including production, government, learning, and research. Then, four target layers, including humanistic aesthetic value, social sustainable value, practical innovation value, and scientific development value, were formed, thereby establishing a solar term culture design strategy indicator model. Secondly, the detailed indicators of the design strategies for solar term culture were employed to verify and evaluate the existing three types of design products, namely, graphic visual design, handicraft design, and commodity packaging design to conduct an overall evaluation and design value judgment, as well as the sustainable development of solar term culture design. Finally, the target levels of the four major aspects of solar term culture design were compared using SWOT analysis, and then, this paper discussed the design strategies, improvement basis, and characteristic developments of three different design types of design products or commodities regarding their design and development, in order to improve and construct a sustainable nonmaterial solar term culture design model.
\end{abstract}

Keywords: solar term culture; sustainability; value; indicator construction and design strategy

\section{Introduction}

\subsection{Research Background and Motives}

With the development of the global economy, the survival of people on earth is threatened by global energy issues, food safety, and environmental problems [1]. How to achieve the sustainable development of material and spiritual civilizations in the context of the pressure on ecology, life, and production by humans is a subject that should be considered by all societies [2]. China was founded on agriculture, and solar term culture is the cultural tradition that governed the life and work cycles of the Chinese people, including the practices of farming on sunny days and reading on rainy days, and working at sunrise and retiring at sunset, which encapsulates the wisdom of the sustainable development of life and nature in the east. As nature's influence on human beings has become less important, modern Chinese people have become disenfranchised, that is, they do not follow the natural rhythms of time and disregard the solar terms [3]. Shi-Cun Yu, the author of the Book of Time: 24 Solar Terms, believes that many urbanized people mistakenly hold that solar terms have nothing to do with them. "We modern people surpass time and lose the sense of time. In the long 
river of solar terms, we need to maintain a spontaneous and introspective view of the relationship among land, environment, history, and society, and should identify the mark and value of solar terms on emotional life [4]."

"The 24 Solar Terms-The Time Knowledge System and Its Practice Formed by Chinese Observing the Sun's Anniversary Movement" was officially included in the representative list of the United Nations Educational, Scientific, and Cultural Organization's intangible cultural heritage of humankind on 30 November 2016 [5]. It is considered a precious treasure left by ancient Chinese farming civilizations, and is still of great significance to modern society. As a unique Chinese time-knowledge system, it profoundly affects the Chinese way of thinking and code of conduct and, thus, it is an important carrier of national cultural identity. The 24 solar terms not only play a guiding role in agriculture, they also embody the Chinese concept of respecting nature, complying with laws, and adhering to sustainable development [6].

Design is an important means of innovation, creation, and entrepreneurship, as well as an important force for cultural reproduction and value dissemination [7]. In the past, design emphasized functional design thinking and functional objective design, while in modern times, design focuses on emotion, culture, and memory [8]. Design concepts not only advocate education, reason, and truth, but pursue freedom, beauty, and joy [9]. The design of solar term culture was conceived within this context to provide a new strategy for the sustainable development of cultural values.

Culture sustainability is one of the indispensable components of sustainability [10]. Culture should become the strategic center of sustainable development due to its impact on international relations from the levels of society, individuals, and natural environment, as well as for its restrictive impact on people's behavior. The integration of culture into development strategies and economic projects will effectively enhance the impact of sustainability [11].

Solar term culture is built on the basis of the philosophy and values of sustainable development, which can exert greater value in the new generation. Values, purpose, and emotions provide a holistic and deep learning experience with transformative power towards a sustainability mindset [12]. Firstly, as intangible cultural heritage, the solar terms are an important way to establish intimate relationships between people, enhance harmonious communication between people and society, develop a friendly environment for humankind, and promote people's understanding of the laws of nature. Secondly, solar term culture provides a sense of identity and continuity for the Chinese community. The Chinese return to themselves and recreate the solar terms through their understanding of the meaning of the solar terms, while experiencing its changes in their life. Thirdly, when we respect, protect, inherit, and promote the culture of the solar terms, it provides a guarantee for cultural diversity and sustainability for the nation's civilization, the country, and the community. Finally, with the power of design, the culture of solar terms will be redefined to exhibit its value. Its application in today's consumer market will not only strengthen the dynamism and viability of solar term culture, it will also help to change irrational resource consumption and consumption models, thus increasing sustainability.

\subsection{Research Goals and Methods}

The 24 solar terms were developed by ancient Chinese people and provided the living basis for farming $[4,6]$. As an important component of traditional culture, solar term culture covers a wide and complex range of fields. Starting from the activation, innovation, and sustainable development of Chinese solar term culture, this study mainly focuses on the design strategies related to solar term culture and develops a sustainable solar term culture design indicator evaluation system through rigorous programs (Figure 1). The hypotheses on which this study is based are as follow:

1. Solar term culture embraces the value of sustainable development;

2. The sustainable value of solar term culture has an impact on design strategy;

3. The sustainable value design indicators of solar term culture can help to evaluate the design products related to solar term culture. 


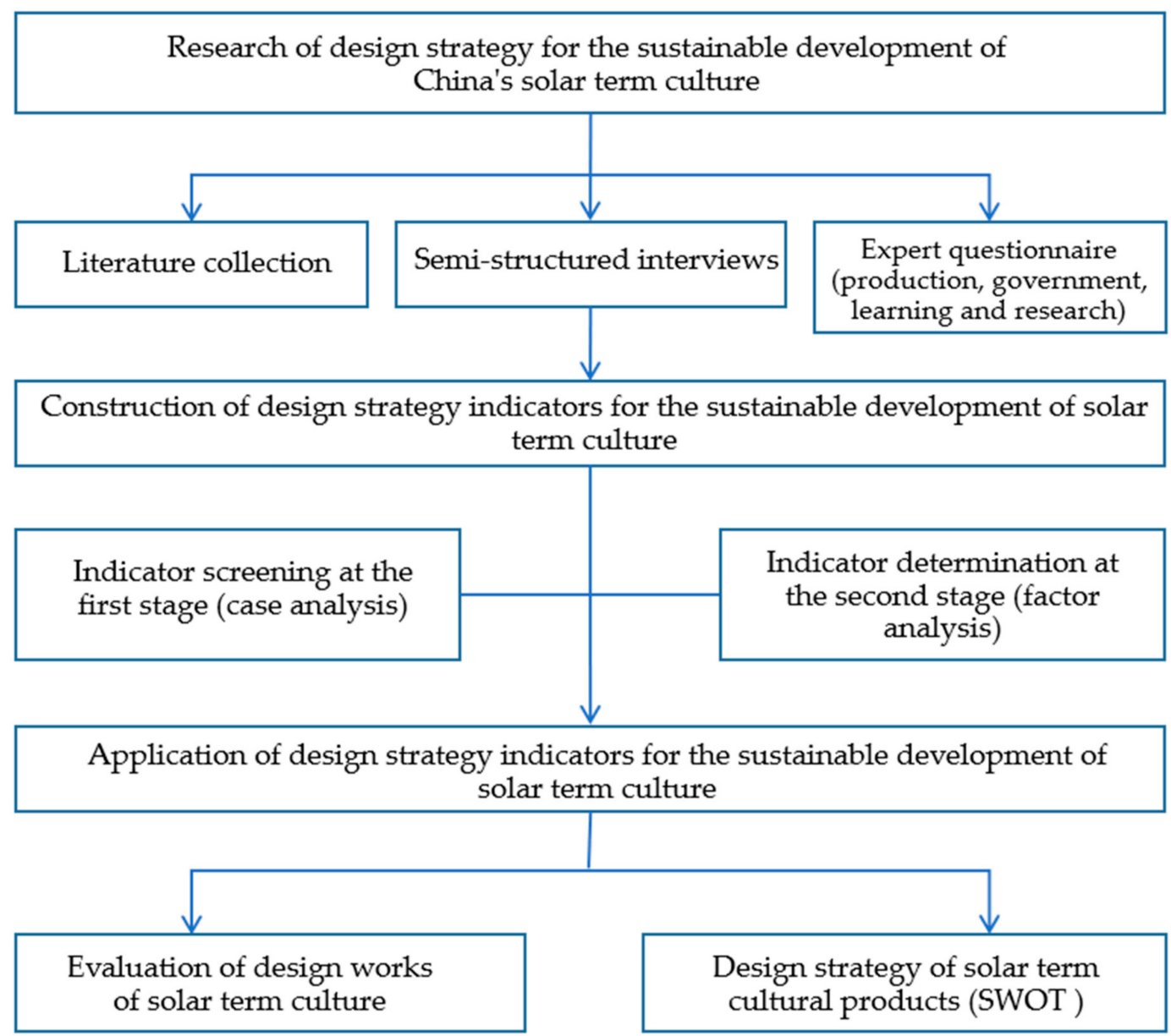

Figure 1. Research process of design strategy for the sustainable development of China's solar term culture.

As one of the world's intangible cultural heritages, the 24 solar term culture has begun to gain attention from academic and design circles; however, most of the discussions only focus on the effective preservation and protection of the current culture. Limited discussions have been conducted on the characteristics and connotations of solar term culture, while very few have discussed its sustainable value and design strategy. With this background, this study took the starting point of the perspectives of design science with the aid of other fields, such as sociology, economics, culturology, and aesthetics, and continued the exploration by employing the approach of combining design methods and practical cases to construct a solar term culture design strategy which put strong emphasis on the value of sustainable development as its main objective.

Based on the above, this study aimed to do the following:

- Through literature review and semistructured interviews, this study investigated the key items of design strategies for the sustainable development of solar term culture, and then further constructed the facets and detailed indicators of solar term culture design by means of an expert questionnaire survey.

- This paper used the value indicator facets of the solar term culture design strategy, as established through research, to verify and evaluate the existing three types of design products and make an overall evaluation and design value judgment.

- Through the value indicator facets of the solar term culture design strategy, this paper discussed the development strategy of different design types of design products or design commodities in their design and development, in order to improve and construct a nonmaterial cultural design development model of the sustainable development of solar term culture design strategy indicators. 


\section{Correlated Research}

\subsection{Meaning of Solar Term Culture}

\subsubsection{Characteristics of Solar Term Culture}

The 24 solar terms were formed in the Yellow River Basin of China. They are based on observing the astronomical phenomena, temperature, precipitation, phenological characteristics, and time series changes in the region, which were gradually adopted by all parts of China and multiple ethnic groups as a time guide for agricultural production and life [13]. The changes of the four seasons reveal the normal state of natural change, and all changes must conform to the laws of nature in order to develop properly [14]. Guanzi said, "seasons fall on specific times." He mentioned the importance of seasons, and pointed out that "not knowing the four seasons will impair the foundation of a country" and that the governance method lies in the importance of properly understanding the nature of seasons [15]. In Shuowen Jiezi, "bamboo joint" refers to the joints restricting the growth of bamboo. The Chinese character for bamboo joint is similar to bamboo and sounds like "ji" in Chinese [16]. Bamboo is a kind of arbor-like herbaceous plant that has knots. The ancients sought inspiration from the section-by-section growth of bamboo. If a year is a whole, one or several time nodes in the middle will indicate one or several important milestones in the year, that is, the origin of a festival [17]. Seasons are important times nodes for Chinese traditional labor production, as well as a spiritual transition ceremony of life culture $[6,14,17]$. For example, at the beginning of spring, there is the custom of whipping spring cows [18]. In ancient times, it was an official labor decree to encourage farmers to help cultivation, but in modern times it has become a festival for people to say goodbye to the old and welcome the new. In rural areas of Southwest Shandong, people are used to sewing colored cotton cloth into rooster ornaments and sewing them on children's clothes and hats [19]. This is commonly known as wearing rooster ornaments in spring, in the hopes that children may be blessed with good luck and grow healthily. In addition, many regions of China have the dietary habit of eating spring cakes [20]. People eat small cakes filled with five vegetables of different colors in order to welcome the beginning of all things, and wish good weather for the crops during the year (Figure 2).

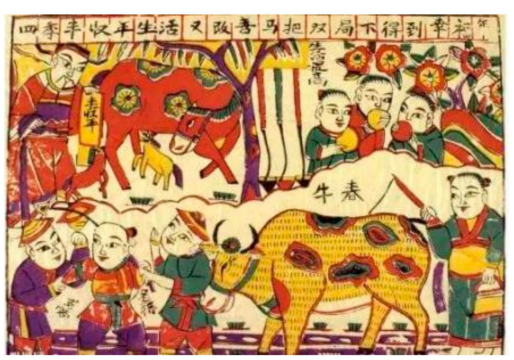

(a)

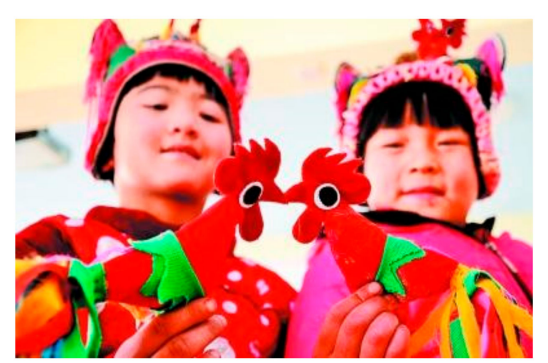

(b)

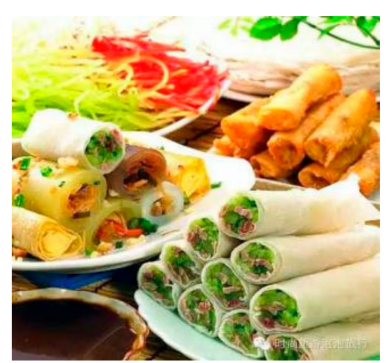

(c)

Figure 2. The Beginning of spring: Custom of whipping spring cows (a), wearing rooster ornaments in spring for happiness (b), dietary habit of eating spring cakes (c).

\subsubsection{Connotation of Solar Term Culture}

According to the position of the sun on the ecliptic, our ancestors divided the year into 24 solar terms [4]. The 24 solar terms can more accurately characterize the phenomenon of climate change and temperature, which has been in use for more than 2000 years and still guides and influences people's use of food, clothing, housing, and transportation $[6,13]$. Each month has two solar terms, one at the beginning of a month called the solar term and one in the middle of a month called the middle solar term (each lasts 15 days). Nowadays, the solar term and middle solar term are collectively referred to as solar terms [21]. According to the meaning represented by their name, the 24 solar terms can be divided into four types. First are the eight solar terms that represent the four seasons: Beginning of Spring, Spring Equinox, Beginning of Summer, Summer Solstice, Beginning of Autumn, Autumnal Equinox, 
Beginning of Winter, and Winter Solstice. Second are five solar terms that represent cold and warm weather: Slight Hea, Great Heat, Limit of Heat, Slight Cold, and Great Cold. Third are seven solar terms that represent precipitation: Rain Water, Grain Rain, White Dew, Cold Dew, Frost's Descent, Slight Snow, and Great Snow. Last are four solar terms that are related to agriculture: The Waking of Insects, Pure Brightness, Grain Full, and Grain in Ear.

\subsection{Sustainable Value of Solar Term Culture}

\subsubsection{Cultural Values}

Culture has value and significance. Only by carrying forward its value model in the new generation can it develop continuously [2]. Cicero, an ancient Roman philosopher, first defined culture as "cultura animi" with the original meaning of cultivation of the soul [22]. David Throsby argued in Economics and Cultural (2003) that the first definition of culture is to describe the attitudes, beliefs, habits, customs, values, norms, etc. shared by a group under an anthropological framework [23]. The second definition is pragmatic and indicates that human beings are engaged in certain activities related to knowledge, morality, and art. Throsby also believed that human cultural activities are characterized by creativity, symbolic meaning, and intellectual property in production activities. He held that cultural values include aesthetic value, which is the value of beauty, harmony, constancy, creativity, and other aesthetic features in cultural works. While aesthetics originally meant perception, it has been extended into the ability to feel and appreciate art [24]. Aesthetics is different from rational cognitive forms, and is a blend of subjective purpose and the objective laws of external objects, resulting in the perception and feeling of human experience [25]. Spiritual value, which is often explained in a religious context, is shared by all humankind from a secular point of view. Its effects include understanding, enlightenment, perception, and insight. Social value indicates that works convey a sense of connection with others, which helps to understand the nature of society and identify values. Historical value aims to explore whether there is any inheritance or historic significance. Symbolic value includes the essence of the meaning conveyed by works and the values conveyed to consumers [26]. True value means that works show a true, original, and unique nature, and that their authenticity and completeness have verifiable value [27]. Culture can be viewed from a macro perspective, including scientific culture, humanistic culture, design culture, and middle culture, including material culture, social culture, economic culture, political culture, ecological culture, science, and technology culture $[2,22,23]$.

\subsubsection{Cultural Value of Solar Terms}

As a national Chinese culture, solar term culture is the accumulation of long-term experience and the crystallization of wisdom, in which people "achieve its perfection by learning the essence of human thoughts and behavior from each other (1882)" [28]. The sustainable value of solar term culture is reflected in Chinese characters, languages, symbols, architecture, products, diet, skills, knowledge, customs, art, etc. [3,4,6,14].

As an intangible cultural heritage, solar term culture is a melting pot of cultural diversity and a guarantee of sustainable development [29]. Design is the driving force promoting the sustainable development of solar term culture, with the power of innovation, creation, and creativity. First, a solar term culture should create its own cultural products and cultural commodities, as creating new value is the future of cultural heritage and protection [30]. UNESCO defined cultural products as consumer goods conveying opinions, symbols, and lifestyles. The concept of cultural commodities was proposed by Ho (2011) to discuss the relationship between culture and goods, explore the representations of cultural information from design information transmission, identify the cultural spirit of products from product evolution, recreate traditional cultural values from design, and extract spiritual connotations from traditional culture, thus giving the design of solar term culture the characteristics of cultural commodities [2]. In the new development process, the sustainable value of solar term culture has become a new design model, in which aesthetic value is prized by modern people. Design aesthetics is 
an applied aesthetic that utilizes aesthetic principles for design and is the basis of design research and production [31]. It takes design beauty as its research core to show abstract and symbolic contents, as well as convey a certain artistic conception, atmosphere, and sentiment with its unique artistic language and symbolic techniques in a bid to arouse people's imagination and sympathy $[25,31]$.

\subsubsection{Sustainable Development of Solar Term Culture}

The sustainable design of solar term culture has several characteristics. First, it is a new development. The designs should adopt new technology, meet new functions, create new situations, and solve functional and expressive problems in the new technical economy. Secondly, it must be reasonable and meet the needs of contemporary people without impairing the ability of future generations to meet their own needs [32]. Thirdly, it is of human nature, social and epochal nature, which all refer to the ultimate purpose of design to serve people's needs in life. The design aesthetics economy also emphasizes the integration of creativity and the core knowledge of life aesthetics to provide an economy with deep experience and high-quality aesthetics [33]. Today, cultural elements related to solar terms are already in various design types, such as graphic visual design, product design, clothing design, space environment design, etc. (Figure 3). These designs not only have usage value, they also have cultural value due to innovation and development. Meanwhile, these different types of design products have excellent performance and arouse consumers' desire through their creativity.
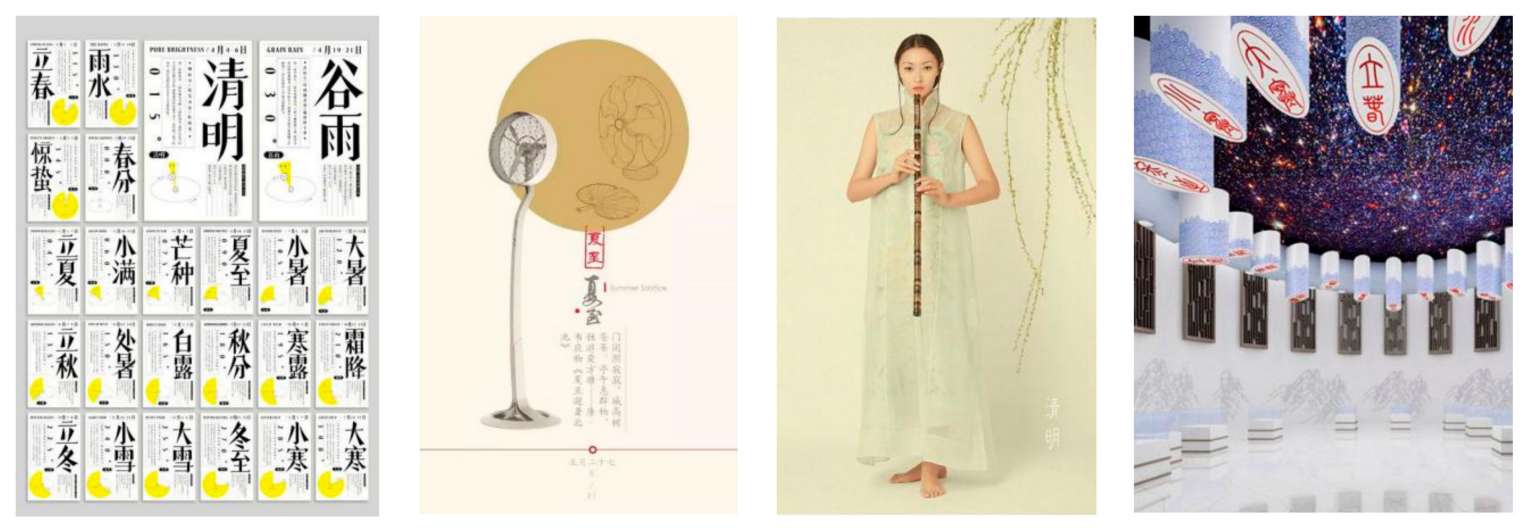

Figure 3. Application and performance of solar culture design elements in graphic design, product design, fashion design, and space environment design.

The changes of contemporary economic forms have boosted the sustainable development of solar term culture. Pine II and Gilmore (1999) co-authored the Experience Economy Era and divided the evolution of economy into agricultural economy, industrial economy, service economy, and experience economy [34]. In terms of the evolution process, the development trend of the economy was initially the commodity economy, that is, the agricultural and industrial economy era, and its production factors were tangible and static products. At this stage, solar term culture was used to guide agricultural production and people's production and life, and finally, to focus on production and output. In the age of the service economy, intangible products became popular; spiritual beliefs, stories and legends, festivals, and other activities in solar term culture were increasingly valued and needed by consumers, and different customized services were provided according to the needs of consumers [4]. The design aesthetics of this age was based on making good products, packaging good wares, creating good brands, and providing good services, but they did not discuss the experience of the overall consumption process. In the era of the experience economy, products or services have become more quality-oriented, and solar term culture aims to create activities that can improve the sense of participation and experience the value of self-existence, with services as the central stage and commodities as material props, thus creating a high value-added economy worthy of consumers' memories and feelings, providing unforgettable experiences to consumers, and satisfying customers' spiritual need for a sense of ritual and holiness [35], 
in order to realize the added value of products and services. Solar term culture is developing and changing constantly, revealing various possibilities of great leaps and sustainable development.

\subsection{Construction of the Design Strategy Indicators of Solar Term Culture}

\subsubsection{Definition and Function of the Design Strategy Indicators of Solar Term Culture}

Indicators are measuring tools that refer to "more than one symbolic representation of input, history, or result, which are established according to different purposes. Indicators can be used for comparison across time, as an absolute standard, or comparisons among and within groups" [36]. A sound indicator system should have important characteristics of theory, hierarchy, diversity, and integrity [37]. From the above, it could be seen that the construction of the design strategy indicators of solar term culture could fully reflect the characteristics and rationality of solar term culture design, as well as meet the needs of industry objectives, ethnic group vision, user groups, designer originality, design attributes, communication, and interpretation of commodity information.

Moreover, the indicators referred to in this study had the meaning of evaluation, and their effectiveness was reviewed through the criteria of indicators. The so-called evaluation possessed a performance evaluation and improvement basis and methods [38-40], as well as characteristic development and other functions. Tyler (1950) regarded evaluation as "the process of determining the degree of achievement of goals" [40], while House (1993) deemed that evaluation means "determining the degree or value of things according to appropriate standards" [41].

Therefore, the design indicators of solar term culture were defined as a certain program and standard employed to carefully evaluate the goal of sustainable development. The function of the design indicators of solar term culture was to review and evaluate whether design works with a solar term culture meaning and whether it could effectively convey the expected goal of sustainable development, or be used as a comparison of strengths and weaknesses. In addition, they could be used as an improvement strategy to analyze the strengths and weaknesses of the sustainable development of solar term culture.

\subsubsection{Implications of the Design Strategy Indicators of Solar Term Culture}

The main purpose of this study is to develop a sustainable design indicator evaluation system of solar term culture through rigorous procedures, and further evaluate the effectiveness of solar term culture design and sustainable development strategies. In addition, the value orientation of the cultural creative design industry and the sustainable development trend of design culture were observed through the measurement of indicators. The basic content of an indicator should include the target and data [42,43]. Chinese solar term culture has a unique aesthetic taste, a wide range of applications, and a universal cultural identity. Establishing sustainable design indicators for solar term culture would be conducive to establishing quantifiable and intuitive value standards through product evaluation and the appraisal of abstract, intangible, and spiritually intangible culture values. To sum up, the design of solar term culture should strive for cultural symbolization and differentiation to highlight the uniqueness of products. Hence, the design indicators of solar term culture should be able to show the cultural characteristics, natural and cultural geographical environment, ethnic thoughts, and other important items of design products, as well as reflect consumer preference characteristics, cultural users, and the core values of recipients in a quantitative manner.

\section{Construction of Design Strategy Indicators of Solar Term Culture}

Based on the research purpose, this study first adopted a literature review and semistructured interviews to determine the design meaning indicators for the sustainable development of the Chinese solar term culture. In the early stage, this study employed semistructured interviews as the research method to clarify the social, economic, and design value of China's solar term culture, as based on sustainable development. The semistructured interview is a kind of informal interview conducted 
according to a conceptual, holistic, and interactive interview outline, which is often used in early study exploration and the collection of problems. Interviewers can flexibly make necessary adjustments to the way they ask questions, the order of interviews, the way of recording, as well as the time and location of the interviews, depending on the actual situation, which also makes the entire process much more convenient. The interview outline of this study mainly includes: 1 . The development status, impact, meaning, and connotation of the culture of the solar terms; 2 . The status and problems of the application of solar term culture in modern product designs, as well as the advantages and disadvantages of the existing products of solar term culture; 3 . Suggestions and views on the re-innovation, redesign, reuse, and recycling, with solar term culture as the core, on the basis of satisfying people's needs through design; 4. The characteristics, meaning, connotation, and value that solar culture products should embrace to achieve the goal of sustainable development. Then, through expert questionnaires, this study screened out the evaluation criteria with professional considerations and established a set of systematic, practical, and sustainable solar term culture design indicators by collecting and sorting expert decision-making methods. The study period was from March 2017 to June 2018.

\subsection{Construction of Hierarchical Structure of Solar Term Culture Design Indicators}

Through expert judgment, this study collected the results of decision-making as the final evaluation indicators of solar term culture product design. Based on the project analysis, factors with low reliability and validity were deleted, and factor extraction and factor reorganization naming were carried out by factor analysis to construct a sustainable design indicator hierarchy for solar term culture. According to the relevant research in the second section, the design of solar term culture requires designers to have a certain understanding and mastery of cultural values. In addition to bringing basic functional requirements to the cultural receivers, they attach importance to the symbolic value of cultural differences in the works and transmission of cultural symbols. In this study, 78 evaluation element projects related to solar terms were collected through a literature review. The reference documents for indicator collection were as follow: (1) Convention on the Protection of Intangible Cultural Heritage (UNESCO, 2003) [44]; (2) Convention on the Protection and Promotion of Diversity of Cultural Expressions (UNESCO, 2005) [45]; (3) Ethical Principles for the Protection of Intangible Cultural Heritage (UNESCO, 2016) [46]; (4) Book of Time: On 24 Solar Terms by Shi-Cun Yu (2017) [4]; (5) Chinese Farming Culture (2012) [47]; (6) 24 Solar Terms Folk Customs (2010) [17]; and (7) Chinese Twenty-Four Solar Terms (2018) [48].

\subsection{Selection of the Design Indicators of Solar Term Culture}

Based on the selection criteria of the experts, this study noted that the design field was diversified and it was necessary to incorporate the opinions of multiple experts. Regarding the selection of experts in the four categories of production, government, learning, and research, we must first narrow down the scope to those with the relevant research background with respect to the 24 solar terms or intangible cultural heritage. In addition, experts with the same knowledge background should have their own views and stances which are different from each other, as design is a process of exploration and construction, and we could not analyze the nature of problems from different perspectives before knowing each other's views on the culture of the solar terms. Moreover, the different ways of thinking, stances, and levels of views of the four types of experts can help us to find more suitable design methods and tools during design exploration, in order to achieve a more effective integrated design. In this regard, based on the technical indicators of the experts selected by Meltsner (1976) and Weimer and Vining (1992) through analysis and politics [49], this study selected four types of experts based on production, government, academia, and research [50]. In this study, a total of 50 expert questionnaires were sent out by purposive sampling. The experts completed either a web-based questionnaire or a paper-based questionnaire. A total of 38 questionnaires were collected, and eight incomplete and incorrect questionnaires were deleted, for a total of 30 valid questionnaires available for this study. The experts participating in the questionnaires included 19 males, 11 females, 7 undergraduates, 7 masters, and 16 doctors. The experts included creative directors in the design industry and design companies, management service experts in 
agricultural government agencies, research experts in agricultural research institutes, design research experts in universities and colleges, etc. Their basic information is shown in Table 1.

Table 1. Basic data of experts of four categories of production, government, learning, and research.

\begin{tabular}{ccccc}
\hline Number & Proportion & $\begin{array}{c}\text { More than } \\
\text { 8 Years of Work } \\
\text { Experience/Number }\end{array}$ & $\begin{array}{c}\text { Master's Degree or } \\
\text { above/Number }\end{array}$ \\
\hline Production & 5 & $16.67 \%$ & $(100.00 \%) 5$ & $(40.00 \%) 2$ \\
Government & 3 & $10.00 \%$ & $(66.67 \%) 2$ & $(66.67 \%) 2$ \\
Academia & 17 & $56.67 \%$ & $(64.71 \%) 11$ & $(94.12 \%) 16$ \\
Research & 5 & $16.67 \%$ & $(60.00 \%) 3$ & $(60.00 \%) 3$ \\
\hline
\end{tabular}

In this study, the experts' opinions were used as data sources to directly delete the indicators that did not reach the consensus of the experts. Instead of conducting multiple expert surveys to reach consensus, this study deleted low consensus indicators directly after the second stage of expert questionnaire collection and statistics. In this study, the principles used by Wang and Wu et al., (2008) [51], Zheng (2005) [52], and Sun (1998) [37] to delete or modify indicators served as the criteria for deleting low consensus indicators. First, through SPSS statistical software, the average value (M) and standard deviation (SD) of each indicator were calculated using the frequency distribution of the descriptive statistics as the basis for evaluation. The principles for deleting or modifying an indicator are as follow. When $M \geq 5.0$, the original condition of the indicator will be maintained; when $5.0>M>4.5$, the experts will modify the indicator. When $\mathrm{M} \leq 4.5$ and $\mathrm{SD} \geq 1$, the original indicator will be deleted, or when $\mathrm{M}$ is too close to 4.5 and $\mathrm{SD} \geq 1$ and experts tend to retain the indicators, the indicator will also be deleted to determine indicators with a high degree of consensus. In this study, the remaining indicators were then screened by the $\alpha$ coefficient verification method through item analysis. Usually, Cronbach's $\alpha$ coefficient values are used to analyze the internal consistency of items under the same structure to determine if they meet the requirement of the $\alpha$ coefficient of the general reliability test, which must be greater than 0.7 [53-55]. Regarding indicators with low or negative correlation to the total score (generally less than 0.3 ), as well as those that could improve the overall $\alpha$ coefficient after deleting the indicator [53], this study listed them as inappropriate indicators for deletion with the aim of determining the high consensus design indicators of solar term culture with strict criteria. After a series of screening processes, the remaining indicators were recompiled into a seven-point Likert scale questionnaire and sent to the experts for the expert survey.

After collecting the experts' questionnaires, factor extraction and classification were carried out through factor analysis using SPSS software, and the structure was named, in order to identify the design index facets of sustainable solar terms and key factors affecting each structure of culture design. The hierarchical structure of the culture design indicators could then be constructed accordingly.

\subsection{Research and Implementation}

After two stages of expert indicator screening, this study constructed the hierarchical structure of solar term culture design indicators and verified the usability of the evaluation indicator with three types of design works. The research results and analysis are shown below.

\subsubsection{Construction of the Design Strategy Indicators of Solar Term Culture}

In the first stage, after the literature review and experts' preliminary selection results, 26 indicators were selected and classified by experts according to their nature. Then, after collecting expert opinions from the questionnaires, the results of indicator screening were summarized and the average value (M) and standard deviation (SD) of the 26 design indicators served as the basis for judgment. In addition, the $\alpha$ coefficient verification method of item analysis was used to screen the indicators. This study further verified the internal consistency reliability of six major dimensions, including 26 indicator 
items in the expert questionnaire. If $\alpha$ is greater than 0.7, it indicates a high confidence level [55]. The verification results show that the Cronbach $\alpha$ values of all six facets reached more than 0.70 . The statistical results show that all structural indicators in this study have considerable credibility, and the 26 design strategy indicators that were conducive to the sustainable development of solar term culture were selected. The statistical results show that there were six indicators of social value: Circulation, timing, phenology, knowledge, regularity, and value; four indicators of humanistic value: Cognition, perception, cultural identification, and subjectivity; five indicators of aesthetic value: Creativity, uniqueness, harmony, communication, and constancy; three indicators of real value: Authenticity, originality, and integrity; four indicators of spiritual value: Cultural belief, inheritance, nationality, and historicity; and four indicators of scientific value: Verification, natural cosmology, timeliness, and objectivity. The above value attributes have the inherent attributes and value trend of the sustainable development of solar term culture. The 26 indicators were recompiled into questionnaires and the definition of each evaluation indicator was sent to the experts for the second-stage official survey.

In the second stage, 38 questionnaires were collected from experts in the four categories of production, government, learning, and research, and eight questionnaires with incomplete and incorrect answers were deleted, for a total of 30 valid questionnaires available for this study. After data collection, this study repeated the reliability and validity analysis and expert indicator review and deleted the indicators that did not meet the measurement standards or overlapped with the original 26 indicators. Finally, the remaining 19 indicators were extracted and named by exploratory factor analysis to construct a hierarchical structure of the design indicators of sustainable solar term culture. The measurement tools used in this study were the principal component method and the maximum varimax method for factor analysis. A total of four factors were extracted with a cumulative explanation variation of $79.64 \%$, a K.M.O. value of 0.673 , and a Bartlett's spherical test value of 542.963 , indicating a certain significance (the significance was 0.000). Four factors were extracted in total (Tables 2 and 3 ).

Table 2. Reliability and validity analysis in stage 2.

\begin{tabular}{lcccc}
\hline \multirow{2}{*}{ Indicators } & \multicolumn{3}{c}{ Factor Load Factor } \\
\cline { 2 - 5 } & Factor 1 & Factor 2 & Factor 3 & Factor 4 \\
\hline Featured root value (before rotation) & 8.996 & 2.887 & 1.943 & 1.306 \\
Variance interpretation rate (before rotation) & $47.35 \%$ & $15.20 \%$ & $10.23 \%$ & $6.87 \%$ \\
Cumulative variance interpretation rate (before rotation) & $47.35 \%$ & $62.54 \%$ & $72.77 \%$ & $79.64 \%$ \\
Featured root value (after rotation) & 5.085 & 4.204 & 3.132 & 2.711 \\
Variance interpretation rate (after rotation) & $26.76 \%$ & $22.13 \%$ & $16.48 \%$ & $14.27 \%$ \\
Cumulative variance interpretation rate (after rotation) & $26.76 \%$ & $48.89 \%$ & $65.37 \%$ & $79.64 \%$ \\
\hline KMO value & \multicolumn{4}{c}{0.673} \\
Bartlett's spherical value & \multicolumn{4}{c}{042.963} \\
$p$ value & \multicolumn{3}{c}{0} \\
\hline
\end{tabular}

Table 3. Factor analysis in stage 2.

\begin{tabular}{|c|c|c|c|c|c|}
\hline \multicolumn{6}{|c|}{ Rotating Component Matrix a } \\
\hline \multirow{2}{*}{ Indicators } & \multirow{2}{*}{ Content } & \multicolumn{4}{|c|}{ Component } \\
\hline & & Factor 1 & Factor 2 & Factor 3 & Factor 4 \\
\hline Constancy & $\begin{array}{l}\text { Design products give people wonderful feelings } \\
\text { in an instant and leave deep memories. }\end{array}$ & 0.863 & 0.136 & -0.101 & -0.029 \\
\hline Transmissibility & $\begin{array}{l}\text { Design products can accurately and effectively } \\
\text { spread and express their sustainable } \\
\text { design value. }\end{array}$ & 0.817 & 0.347 & 0.024 & 0.098 \\
\hline Cultural identity & $\begin{array}{l}\text { People-oriented design works of solar terms } \\
\text { have their own cultural identification symbols, } \\
\text { tokens, and codes. }\end{array}$ & 0.809 & 0.216 & 0.080 & 0.097 \\
\hline
\end{tabular}


Table 3. Cont.

\begin{tabular}{|c|c|c|c|c|c|}
\hline \multicolumn{6}{|c|}{ Rotating Component Matrix a } \\
\hline \multirow{2}{*}{ Indicators } & \multirow{2}{*}{ Content } & \multicolumn{4}{|c|}{ Component } \\
\hline & & Factor 1 & Factor 2 & Factor 3 & Factor 4 \\
\hline Harmony & $\begin{array}{l}\text { Design products embody the idea of harmonious } \\
\text { coexistence between people, people and objects, } \\
\text { and people and the environment. }\end{array}$ & 0.794 & 0.215 & 0.255 & 0.241 \\
\hline Perception & $\begin{array}{l}\text { Design products reflect people's certain emotions } \\
\text { and real feelings in treating solar terms and } \\
\text { cultural items. }\end{array}$ & 0.792 & 0.377 & 0.072 & 0.026 \\
\hline Uniqueness & $\begin{array}{l}\text { Design products have unique aesthetic taste in } \\
\text { the expression of design aesthetics. }\end{array}$ & 0.785 & 0.183 & 0.402 & -0.052 \\
\hline Nationality & $\begin{array}{l}\text { Design products help to strengthen the nation's } \\
\text { cultural sustainable development and the } \\
\text { construction of its identity. }\end{array}$ & 0.308 & 0.850 & 0.213 & 0.089 \\
\hline Cyclicity & $\begin{array}{l}\text { Design products reflect the laws and cycles of } \\
\text { time, space, and human movement. }\end{array}$ & 0.253 & 0.811 & 0.056 & 0.216 \\
\hline Timing & $\begin{array}{l}\text { Design products highlight the change and } \\
\text { feeling of time. }\end{array}$ & 0.228 & 0.797 & 0.177 & 0.379 \\
\hline Cognition & $\begin{array}{l}\text { Design products have enlightening significance } \\
\text { in people's understanding of nature and } \\
\text { the environment. }\end{array}$ & 0.147 & 0.771 & 0.016 & 0.525 \\
\hline Historicity & $\begin{array}{l}\text { In designing products, we can find historical } \\
\text { memories and past experiences. }\end{array}$ & 0.159 & 0.715 & 0.386 & -0.113 \\
\hline Substantiality & $\begin{array}{l}\text { Design products reflect the characteristics and } \\
\text { values of farmers, rural areas, and agriculture. }\end{array}$ & -0.014 & 0.211 & 0.781 & 0.305 \\
\hline Subjectivity & $\begin{array}{l}\text { Design products express people's subjective } \\
\text { consciousness, self-practice, and existence } \\
\text { significance. }\end{array}$ & 0.019 & 0.557 & 0.733 & 0.050 \\
\hline Creativity & $\begin{array}{l}\text { Design products reflect people's creativity to } \\
\text { transform and make use of nature. }\end{array}$ & 0.547 & 0.097 & 0.728 & 0.075 \\
\hline Integrity & $\begin{array}{l}\text { Design products reflect the complete experience } \\
\text { and process of agricultural activities. }\end{array}$ & 0.138 & 0.305 & 0.665 & 0.486 \\
\hline Verifiability & $\begin{array}{l}\text { Design products reflect the rigor, operability, } \\
\text { and verifiability of scientific practice. }\end{array}$ & -0.011 & 0.221 & 0.145 & 0.832 \\
\hline Natural cosmology & $\begin{array}{l}\text { Design products are macroscopic and can } \\
\text { produce imagination of nature, the universe, etc. }\end{array}$ & -0.007 & 0.293 & 0.482 & 0.726 \\
\hline Objectivity & $\begin{array}{l}\text { Design products reflect an objective } \\
\text { understanding of nature and the essence of social } \\
\text { and economic development. }\end{array}$ & 0.558 & 0.062 & 0.310 & 0.654 \\
\hline Inheritance & $\begin{array}{l}\text { Design products can transmit and inherit the } \\
\text { inner spiritual connotation of solar term culture. }\end{array}$ & 0.173 & 0.573 & 0.010 & 0.627 \\
\hline \multicolumn{6}{|c|}{$\begin{array}{l}\text { Extraction method: Principal component analysis. } \\
\text { Pivoting method: The maximum variation method of Kaiser regularization is used. }\end{array}$} \\
\hline \multicolumn{6}{|c|}{ a. Convergence rotation in seven iterations. } \\
\hline
\end{tabular}

\subsubsection{Naming the Design Strategy Indicators of Solar Term Culture}

This study aimed at the sustainable development of solar term culture, analyzed the social value, humanistic value, aesthetic value, real value, spiritual value, scientific value, and other aspects of solar term culture, considered the content of each facet indicator after indicator extraction, and named the four facets after factor analysis: Humanistic aesthetic value, social sustainable value, practical innovation value, and scientific development value. The first level of the constructed hierarchical structure of evaluation indicators was the goal level, while the second level (objective level) was the evaluation design indicator structure of solar term culture [56]. After the extraction and statistics of each factor, the contents of the four textures are as follow: 
This study presents four major facets (Figure 4). First, from the perspective of humanistic aesthetics, it could be seen that design products can bring people instant good feelings, leave deep memories, express sustainable design value, embody their individual symbols of cultural recognition, show unique aesthetics and taste, and reflect people's emotions and feelings towards things. Secondly, the social sustainability value reflects whether design can reflect the regularity of time and space, and whether it shows the changes and the order of solar terms and time, in order to inspire people's understanding of nature through design works, thus awakening memories and nostalgia of the past. Thirdly, the practice innovation value is based on solar term culture and comes from agriculture, the countryside, and farmers, while innovation practice reflects the agricultural value, expresses people's subjective consciousness, transforms nature, and makes use of the creative ability of nature. Finally, the scientific development value and the design of solar terms should reflect the rigors of scientific practices and arouse imaginations of the sun, moon, stars, and the vast universe, etc., in order to produce an objective understanding of nature and show the essence of society, as well as inherit the inherent spirit of solar term culture.

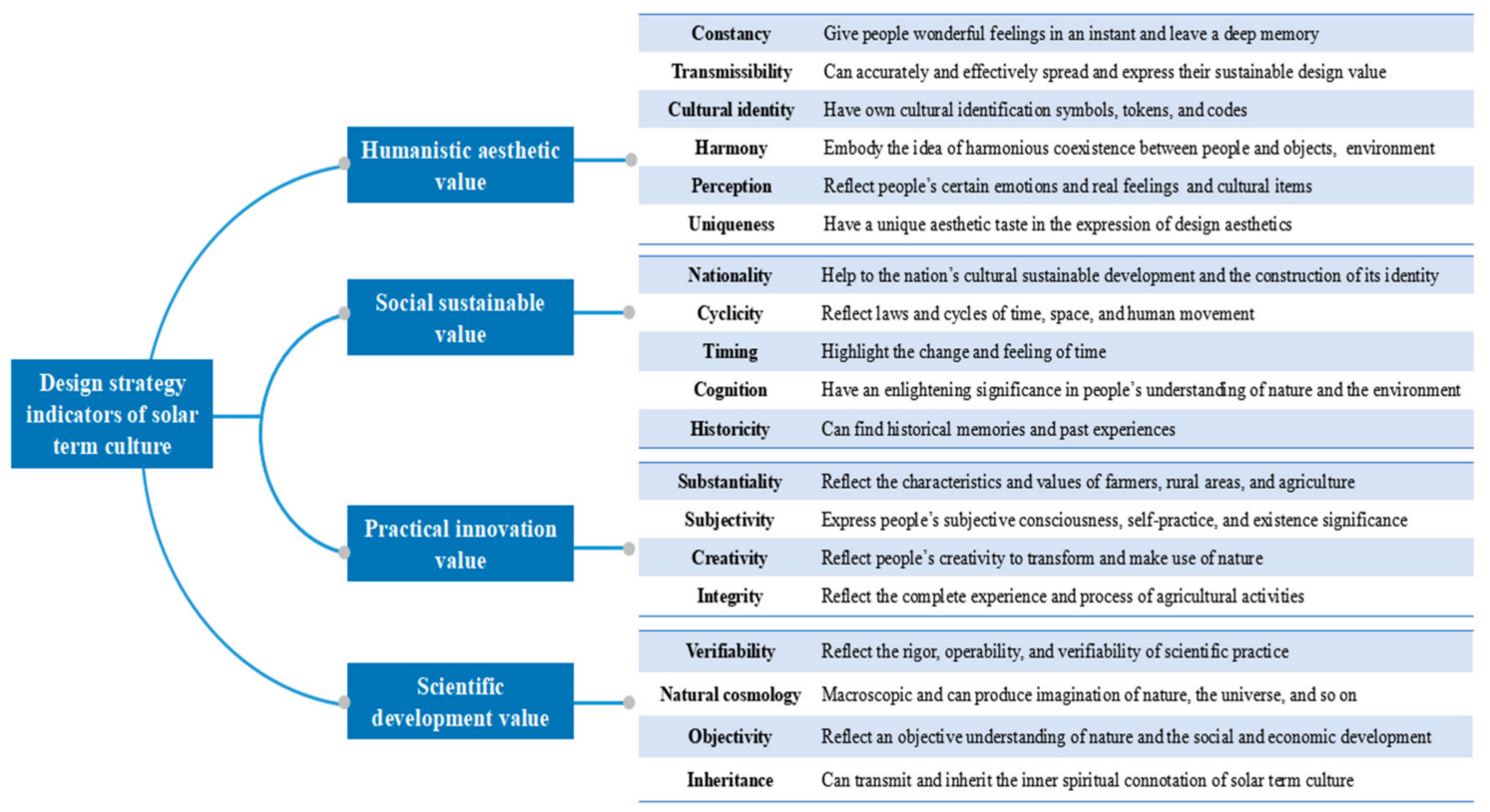

Figure 4. Design strategy indicator model of solar term culture.

\section{Application and Evaluation of the Design Strategy Indicators of Solar Term Culture}

This study evaluated and applied the theoretical, hierarchical, pluralistic, and complete nature of the design strategy indicators of solar term culture. The construction of the design strategy indicators of solar term culture could fully reflect the characteristics and rationality of design products, as well as effectively explain the communication between design products and design commodity information. First, the indicators themselves have the meaning of evaluation. Through the indicator details, their effectiveness could be reviewed to determine the process of achieving the goal and the degree or value of things according to the appropriate criteria. The design strategy of solar term culture refers to reviewing and evaluating whether design works with solar term cultural meaning could effectively convey the expected goal of sustainable solar term culture. Secondly, the design strategy indicators of solar term culture were used to analyze the strengths and weaknesses of design products and design commodities, in order to improve their design strategies, basis, and method, and their characteristic development was applied to achieve activation and sustainable development of intangible culture. Efforts were made to understand and evaluate the cultural value of solar terms and related design works, in order to understand the characteristics and strengths of design, identify weaknesses and improvement methods, and show the various levels in a pluralistic and complete manner. This was an important process for activating intangible cultural connotations and promoting the sustainable 
development of intangible cultural values after the construction of design indicators in the various fields of production, government, learning, and research in the design field.

\subsection{Evaluation of Design Works of Solar Term Culture}

In addition to evaluating the strengths and weaknesses of a single solar term culture design product, the design strategy indicators of solar term culture, as constructed by this study, could also be used to compare the effectiveness of cultural values of different types of solar term designs. According to the results of the expert discussions, graphic visual design, handicraft design, commercial design, and packaging design were evaluated, respectively (Table 4).

Table 4. Evaluation samples of three types of design products.

\begin{tabular}{lll}
\hline Type & Work 1: Graphic Visual Design & Work 2: Handicraft Design
\end{tabular}

This study invited five experts from the four categories of production, government, academia, and design research to evaluate the usability of the design strategies of solar term culture at this stage. The experts included two designers, two design researchers, and one researcher in the agricultural field, all of whom have more than 10 years of professional experience.

After discussion, the experts selected three types of design products as the evaluation samples, and scored three products according to 19 evaluation indicators of the design strategy of solar term culture, with scores ranging from 1 to 10 points. The higher the score, the more the solar term culture design conformed to the connotations of the indicators. Before the evaluation process, the experts read relevant materials concerning the design background of the products, as well as the developers' business philosophy and vision.

In this study, three different types of solar term culture designs were selected as evaluation subjects, and three design cases with a sense of design were selected to apply the 19 evaluation indicators of the design strategies of solar term culture to conduct product analysis, in order to verify the sustainable use of the design strategies of solar term culture in design innovation (Figure 5).

Design work 1 is a graphic visual design poster. This work took the name and font of the 24 solar terms as the design subject to form a new design image through the recombination of the 24 solar term characters. Using a single item of the 19 indicators for evaluation, this work had the highest score in cultural identification (7.4) and transmissibility (7.2), respectively, as the design elements of the two-dimensional graphic poster were mainly composed of the characters that are the most representative of Chinese cultural symbols and, thus, are images easily accepted by recipients. The poster was designed for the purpose of effectively transmitting information, and its visual influence and impact were the most attractive. The lowest score items were subjectivity (2.6), substantiality (2.8), and historicity (2.8). These graphic design works were characterized by inactive recipient participation, low self-practice 
content, and rare expressive force and historical development of solar term culture, as compared with visual arts with a strong sense of modernity, resulting in a low score by the evaluation experts.

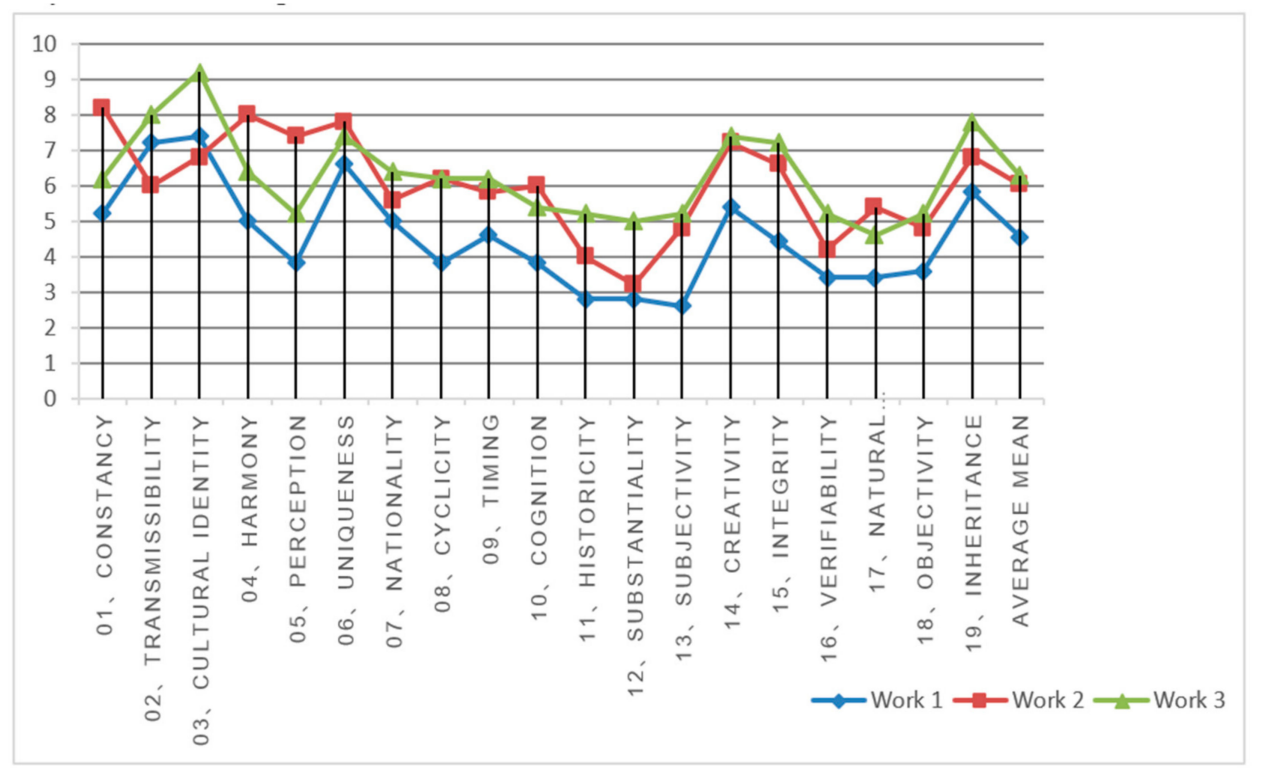

Figure 5. Score of three types of design product samples.

Design work 2 is a traditional handicraft design. These glasses were inspired by the colors of spring, summer, autumn, and winter, and they made use of poetry and beauty through the adoption of Chinese paintings. Using indicators for comparison and evaluation, this work had the highest scores in constancy (8.2), harmony (8), and uniqueness (7.8). This work is three-dimensional artwork with certain functionality, and applied natural scenery and an artistic rendering of different seasons in its external production in a bid to bring people instant beautiful feelings after using the product, to associate people with the idea of harmonious coexistence between people and the environment, and to leave a good memory. The score was lowest in substantiality (3.2) and historicity (4). Although this work depicts natural elements, it did not include more elements that could reflect the characteristics of farmers, rural areas, or agriculture, and it did not show experience related to historical memory or the past; therefore, the scores of the indicator items were lower.

Design Work 3 is a commodity and packaging design. This commodity was sold as beer with different tastes based on the 24 solar terms' relevant taste sensation. Its packaging design featured the name and characters of the solar terms and matched the colors and symbols of different solar terms; thus, the packaging form of the product was unified, while the details were varied to match the inherent quality of the product. Using indicators for comparison and evaluation, this work had the highest scores in cultural identification (9.2), transmissibility (8), and inheritance (7.8). This work employed the concept and elements of solar term culture in its merchandise and outer packaging, and it applied the character code in packaging to deepen the recognition of traditional culture. In its interaction and experience with consumers, it could enhance both visual feelings and taste feelings, which improved its transmissibility, while the commodity added traditional intangible cultural connotations, which enabled the recipients to have an advantage in conveying cultural values and inheriting the inherent spirit of culture on a psychological level. However, in terms of natural universe (4.6) and substantiality (5), the score was the lowest. As a part of the market and economy, commodities limit people's imagination and creativity to the natural universe and the vast universe.

This study used 19 evaluation indicators of the design strategy of solar term culture to analyze and evaluate three types of design works, which could effectively review and evaluate the expected goal of sustainable development of solar term culture. In addition, these indicators could evaluate the comparison of three types of solar term cultural product designs. The average score of work 1 was 
4.55 , the average score of the handicraft design was 6.04 , and the average score of the commodity and packaging design was 6.28 , which shows that design products with solar terms and cultural connotations within a specific range could be evaluated and compared with each other horizontally to understand the strengths and weaknesses of a certain type of design product. Secondly, the strengths and weaknesses of different products under the same category of indicators could be evaluated vertically, for example, under the creativity indicator. The three types were 5.4, 7.2, and 7.4, respectively, which indicated that products with the commodity and packaging design type had the highest creativity. After analysis of relevant reasons, it was found that commodities should be constantly innovated and improved to meet the needs of the market. Traditional beer not only changes its outer packaging to incorporate the visual symbol of solar term culture, it also develops different tastes according to different solar term characteristics, thereby providing consumers with more choices and creating new values for the brand.

\subsection{Design Strategy of the Design Works of Solar Term Culture}

The design strategy indicators of solar term culture were used to evaluate the cultural value of the solar terms, the characteristics, and strengths of related design works, identify weaknesses, improve strategies and methods, and finally, present the possibility of solar term culture application in a pluralistic and complete manner.

According to the research, the design strategy indicators of the solar terms were employed to analyze and apply the strategies of three types of designs: Graphic visual design, handicraft design, and commodity and packaging design. First, according to the scores and evaluations of the three types of design works by five experts, the scores were summarized and drawn according to their humanistic aesthetic value, social sustainable value, practical innovation value, and scientific development value, thereby laying the foundation for further analysis and the application of strategies. Secondly, strategy analysis was based on the four major facets of the design strategies of solar term culture, which was macroscopically and holistically compared with the 19 sub-indicator items. It could be seen that among the three kinds of design works, the value judgment of one item was obviously lower than that of the other two works, and the comprehensive score of the humanistic aesthetic value in the four facets was higher than that of the other three dimensions. Finally, using the SWOT analysis method, the strengths, weaknesses, opportunities, and challenges, which are commonly-used analysis tools, of each design type could be effectively analyzed (Figure 6 and Tables 5-7) in combination with the design structure of solar term culture.

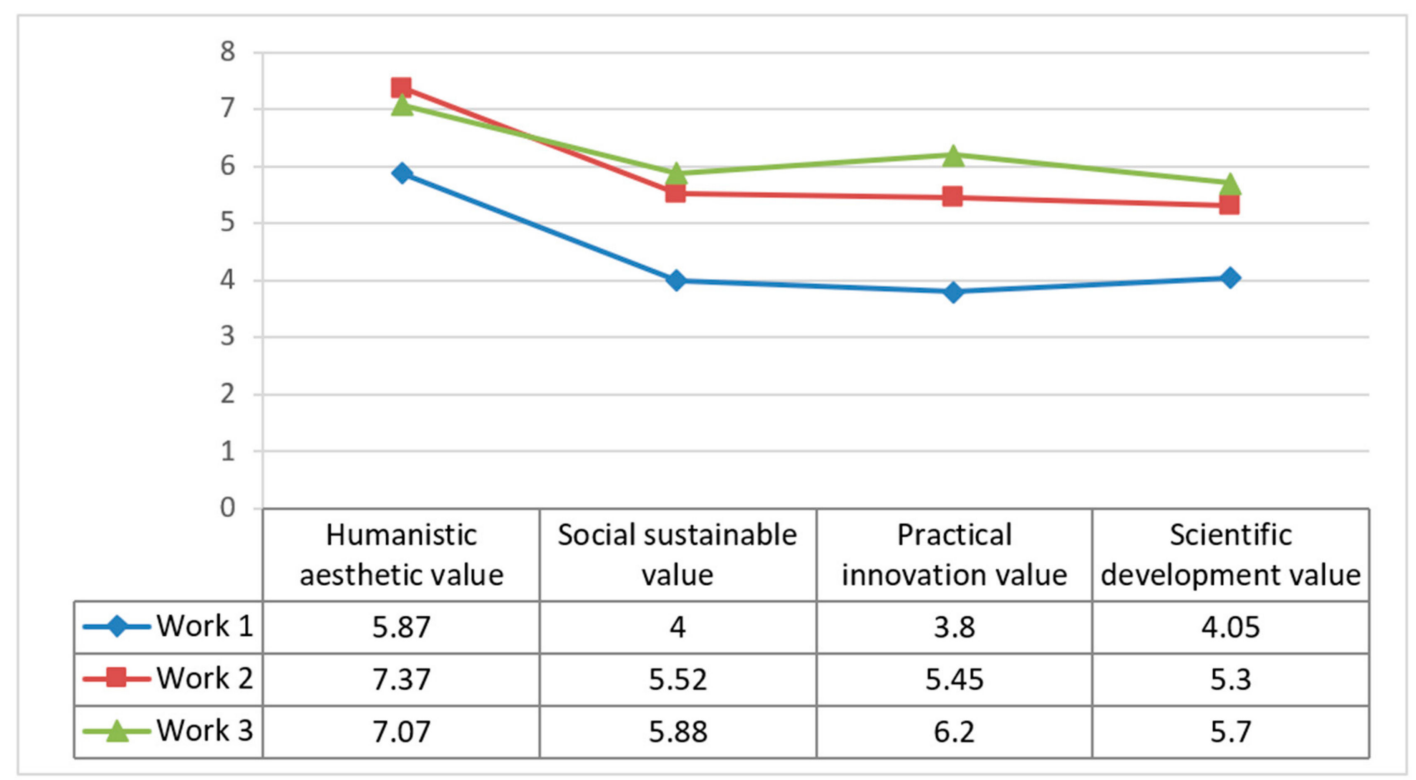

Figure 6. Scores of the four structural facets for three types of design product samples. 
Table 5. SWOT analysis of print works.

\begin{tabular}{ll}
\hline \multicolumn{1}{c}{ Strengths } & \multicolumn{1}{c}{ Weaknesses } \\
\hline $\begin{array}{l}\text { 1. Strong font symbol recognition. } \\
\begin{array}{l}\text { 2. Certain strengths in transmission. } \\
\text { 3. Unique aesthetic features. }\end{array}\end{array}$ & $\begin{array}{l}\text { 1. Unable to play the role of the five senses well. } \\
\text { 2. Poor sensory perception and weak connection } \\
\text { of time series. } \\
\text { 3. Difficult to express people's subjective consciousness, } \\
\text { self-practice, and existence significance. }\end{array}$ \\
\hline \multicolumn{1}{c}{ Opportunities } & \multicolumn{1}{c}{ Threats } \\
\hline $\begin{array}{l}\text { 1. Give full play to the strengths of easy identification } \\
\text { and deepen the audience's cognition. }\end{array}$ & $\begin{array}{l}\text { 1. Promote interaction with people's five senses. } \\
\text { 2. Applicable to a wide range of publicity. }\end{array}$ \\
$\begin{array}{l}\text { 3. Give full play to the strengths of sound, meaning, } \\
\text { and shape of the plain font to make it more complete. }\end{array}$ & 3. Enhance human interaction and participation. \\
\hline
\end{tabular}

Table 6. SWOT analysis of crafts design.

\begin{tabular}{|c|c|}
\hline Strengths & Weaknesses \\
\hline $\begin{array}{l}\text { 1. Unique usability. } \\
\text { 2. Beauty of material and form. } \\
\text { 3. Unique aesthetic taste. }\end{array}$ & $\begin{array}{l}\text { 1. Poor transmissibility. } \\
\text { 2. Weak construction and identification } \\
\text { of national culture. } \\
\text { 3. People's poor understanding of nature } \\
\text { enlightenment, scientific rigor, and verifiability. }\end{array}$ \\
\hline Opportunities & Threats \\
\hline $\begin{array}{l}\text { 1. Give full play to the strengths of traditional technology } \\
\text { and deepen the audience's cognition. } \\
\text { 2. Combine materials with modern technology. } \\
\text { 3. Give full play to the artistic strengths of interaction, } \\
\text { craftsmanship, and temperature to make it more modern. }\end{array}$ & $\begin{array}{l}\text { 1. Promotion, transmission, and publicity. } \\
\text { 2. Break traditional shackles and give full play } \\
\text { to artistic charm. } \\
\text { 3. Enhance the scope of application and interaction. }\end{array}$ \\
\hline
\end{tabular}

Table 7. SWOT analysis of commodity and packaging design.

\begin{tabular}{|c|c|}
\hline Strengths & Weaknesses \\
\hline $\begin{array}{l}\text { 1. Have complete systematicness and regularity. } \\
\text { 2. Strong product packaging and product identification. } \\
\text { 3. Substantiality of products can affect consumers' } \\
\text { feelings and happiness of beauty. }\end{array}$ & $\begin{array}{l}\text { 1. Relatively strong system and large amount of } \\
\text { design resources. } \\
\text { 2. Cultural commodities with certain rules are prone to } \\
\text { cause creative deficiency. } \\
\text { 3. Consumers ignore sustainability and environmental } \\
\text { protection in their understanding, easily leading } \\
\text { to waste. }\end{array}$ \\
\hline Opportunities & Threats \\
\hline $\begin{array}{l}\text { 1. Give full play to the strengths of national culture and } \\
\text { deepen the audience's cognition. } \\
\text { 2. Give full play to individual characteristics of a single } \\
\text { theme. } \\
\text { 3. Give full play to the artistic strengths of interaction, } \\
\text { technology, and design to make it more modern. }\end{array}$ & $\begin{array}{l}\text { 1. Improve the group utility of commodities, while } \\
\text { reducing waste. } \\
\text { 2. Break traditional shackles and give full play to } \\
\text { artistic charm. } \\
\text { 3. Enhance the scope of application and interaction. }\end{array}$ \\
\hline
\end{tabular}

To sum up, after relevant research, the design strategy indicators of solar term culture had the function of evaluation and appraisal, and their effect could be reviewed through the indicator details. The degree or value of design could be determined according to appropriate standards, and the expected goal of the sustainable development of solar term culture could be effectively reviewed. The design strategy indicators of solar term culture could be used to analyze the strengths and weaknesses of design products, and could be used as an improved design strategy, commercial strategy, and marketing strategy to achieve activation and the sustainable development of intangible culture. Firstly, we could integrate cultural identity into the "Chinese style" creative goods. The 24 solar term culture incorporates strong Chinese cultural symbols and symbolic codes, which can effectively enhance the cultural identity of consumers. Secondly, the aesthetics of the solar terms also promote the aesthetics of the commodity to which it is incorporated. Regarding the growing needs of the consumer's spiritual pursuit, the integration 
of aesthetic images of different solar terms into the product and design is effective in improving product quality and increasing consumption motivation. Moreover, promotional activities themed on solar terms help to boost experience consumption. Corresponding business activities can be launched at different time points of the solar terms cycle, so as to make folk customs, diet, and habits become the features of consumer experience and consumption. Finally, we should build a "responsible" solar term culture brand. The solar terms themselves enjoy the connotation of cyclic, orderly, natural, and ecologically sustainable development, which, in their integration into the business brand construction, can create a consumer-friendly brand image and cultivate a responsible and healthy corporate culture. These indicators are theoretical, hierarchical, pluralistic, and complete. Building the design strategy indicators of solar term culture could fully reflect the characteristics of the design products of solar term culture and meet multiobjective visions. It is an important process to activate intangible cultural connotations and promote the sustainable development of intangible cultural values.

\section{Conclusions and Suggestions}

\subsection{Conclusions}

Through literature review, interviews, and expert opinions, this study constructed a hierarchical structure of the design indicators of solar term culture, which could be developed in a sustainable manner, in the hopes of clarifying the value factors of Chinese solar term culture design and activating sustainable, harmonious, and strategic development of nonmaterial culture through the power of design. Through the construction of design strategy, and later evaluation and application, new development ways can be adopted for traditional culture in various fields, such as production, government, learning, and research. Meanwhile, it could help the design community to evaluate the quality of the sustainable development of cultural design and effectively enhance the value and design connotations of Chinese culture.

Through a two-stage expert questionnaire, factor analysis, and factor extraction, this study constructed the design strategy indicators of solar term culture, including the four major facets of the value of humanistic aesthetics, the value of social sustainability, the value of practical innovation, and the value of scientific development, as well as 19 detailed evaluation indicators. These facets and indicators are key factors that affect the success or failure of the design strategies of solar term culture. Through these detailed indicators, the design of Chinese solar term culture can be evaluated more objectively, concretely, and completely.

Finally, the feasibility of the three design types with a solar term culture theme was verified and evaluated. The results show that the evaluation indicators, as constructed by this study, could effectively evaluate the sustainable development effects of the solar term culture design of a single design work or different kinds of design works, and according to the evaluation results, this study put forward cultural strategies for the sustainable development of solar term culture in contemporary society. The design strategy indicators of solar term culture were used to analyze the strengths and weaknesses of design products and design commodities, in order to improve design, business, and marketing strategies, as well as achieve the activation and sustainable development of intangible culture. Finally, it activated the connotations of intangible culture and promoted more possibilities for the sustainable development of intangible cultural values.

\subsection{Research Limitations and Recommendations}

The limitations of this study firstly lie in the data collection, meaning the lack of discussion on the connotations of solar term culture, and the shortage of papers regarding sustainable value and design strategy, which affects the basic discussion of this paper. Another limitation is that the research gathered samples through convenient sampling and the "snowball" approach, in which there may be individual differences. Therefore, it is also hoped that future research of related topics can be improved by reviewing the experience of this research. This study quantitatively evaluated cultural creative 
products through the design strategy indicators of solar term culture; thus, there was a lack of business orientation in this study, and consumers' views on cultural design issues should be discussed in a more in-depth manner. Future study may focus more on the quality of solar term culture design, explore the reasons for the influencing factors of solar term culture design, as well as their relationship with each other, and conduct a more in-depth analysis of users' perceptions of solar term culture design, in order to supplement the shortage of quantitative results from experts' views alone. In addition, this study mainly adopted the opinions of experts from mainland China and Taiwan. It is suggested to incorporate the opinions of Chinese and non-Chinese experts in different regions regarding the sustainable development of solar term culture, which will make the study of design indicators of solar term culture more extensive and help to develop sustainable strategies for cultural design.

Author Contributions: All authors contributed to the paper. W.-T.L. collected data, C.Y. wrote the manuscript with the supervision from W.-T.L., and M.-C.H. acted as a corresponding author.

Funding: This research received no external funding.

Conflicts of Interest: The authors declare no conflict of interest.

\section{References}

1. Holmgren, D. Permaculture: Principles \& Pathways beyond Sustainability, 1st ed.; Earth Passengers: Taipei, Taiwan, 2014; pp. 23-28. ISBN 9789868806016.

2. Ho, M.C. Thoughts on the core value and core competence of design. J. Chaoyang Univ. Technol. 2011, 16, 31-44. [CrossRef]

3. Hsiung, T.T. Hakka Culture Relates to Taiwan Hakka Proverbs of the Twenty-Four Solar Terms. Master's Thesis, National Yunlin University of Science \& Technology, Yunlin, Taiwan, 2006, unpublished.

4. Yu, S.C. Book of Time: On 24 Solar Term, 1st ed.; China Friendship Publishing Company: Beijing, China, 2017; pp. 71-84. ISBN 9787505739338.

5. Xinhua Net. Available online: http://www.xinhuanet.com/politics/2016-11/30/c_129385180.htm (accessed on 21 March 2017).

6. Shen, Z.Z. Textual Research on the Forming Time of 24 Solar Terms. South. Cult. 2001, 1, 53-56.

7. Yang, T.L.; Ho, M.C.; Lee, C.F. A Strategy of Innovation Entrepreneurship in Cultural \& Creative Industries. J. Des. Res. 2006, 6, 119-127. [CrossRef]

8. Zhang, W.T. On the Beauty of Artistic Conception in Modern Logo Design. Master's Thesis, Nanjing Normal University, Nanjing, China, 2013, unpublished.

9. Hu, Y.P.; Zhang, D.S. Emotional Semantic Research on the Form of Daily Ceramic Products. J. Art Des. 2017, $3,43-47$.

10. Lin, J.; Cai, J.; Han, Y.; Zhu, H.; Cheng, Z. Culture Sustainability: Culture Quotient (CQ) and Its Quantitative Empirical Application to Chinese Cities. Sustainability 2016, 8, 1235. [CrossRef]

11. UNESCO. Cultural Column. Available online: http://www.unesco.org/new/zh/culture/ (accessed on 13 February 2017).

12. Jan, H.; Isabel, R. Deep learning for a sustainability mindset. Int. J. Manag. Educ. 2018, 16, 460-467.

13. Chen, Y.I.; Chen, W.F.; Huang, R.C.; Huang, S.Z. The Implications of Chinese 24 Jieqi on An Example of Folk Festival Industry in Taiwan Management Activities. J. Chin. Manag. Dev. 2009, 1, 223-245. [CrossRef]

14. Zhou, H. Twenty-four solar terms folk culture characteristics. J. Shenyang Norm. Univ. (Soc. Sci. Ed.) 2015, 39, 145-147.

15. Chinese Philosophy Book Electronic Plan. Available online: https://ctext.org/guanzi/si-shi/zhs (accessed on 25 March 2017).

16. Zdic Net. Available online: http:/ / www.zdic.net/z/22/js/8282.htm (accessed on 26 March 2017).

17. Kao, C.I. 24 Solar Terms Folk Customs, 1st ed.; China Social Press: Beijing, China, 2010; pp. 43-53. ISBN 9787508730424.

18. READ01. Available online: https://read01.com/EOmM44.html\#.W760auhubIU (accessed on 28 March 2017).

19. Wang, S.F. The custom of the beginning of spring in southern Shandong. Available online: http://www.feng suwang.com/jieri/jieqi8875.asp (accessed on 28 March 2017). 
20. TECH-FOOD. Available online: https://www.tech-food.com/kndata/detail/k0227976.htm (accessed on 28 March 2017).

21. Jing, M. The Evolution of the Ancient Chinese Solar Terms and the Formation of the Twenty-Four Seasons. J. Huai Hua Univ. 2011, 30, 9-11.

22. Wikipedia. Cultural indication. Available online: https:// zh.wikipedia.org/wiki/\%E6\%96\%87\%E5\%8C\%96 (accessed on 13 February 2017).

23. David, T. Economics and Cultural, 1st ed.; Art and Collection Co., Ltd.: Taipei, Taiwan, 2003; pp. $33-39$. ISBN 9789572832.

24. Chinn, P.L.; Kramer, M.K. Integrated Theory and Knowledge Development in Nursing, 7th ed.; Elsevier-Mosby: St. Louis, MO, USA, 2008.

25. Lang, Y. Foundations of Aesthetics, 4th ed.; Peking University Press: Beijing, China, 2009; pp. $22-47$. ISBN 9787301047439.

26. He, L.J.; Lin, Y.M. Symbol and Abstract. J. Soc. Sci. Hunan Norm. Univ. 2006, 35, 47-49.

27. Victor, P. Design for the Real World, 1st ed.; CITIC Publishing House: Beijing, China, 2012; pp. $39-67$. ISBN 9787508634135.

28. Literature and Science. Available online: http://homes.chass.utoronto.ca/ \{\}ian/arnold.htm (accessed on 5 March 2017).

29. United Nations Convention and Declaration Search System. Available online: http://www.un.org/zh/docu ments / treaty / files / A-CONF-165-14.shtml (accessed on 5 March 2017).

30. Härkönen, E.; Huhmarniemi, M.; Jokela, T. Crafting Sustainability: Handcraft in Contemporary Art and Cultural Sustainability in the Finnish Lapland. Sustainability 2018, 10, 1907. [CrossRef]

31. Xing, Q.H. Design Aesthetics, 1st ed.; Southeast University Publishing: Nanjing, China, 2011; pp. 13-46. ISBN 9787564126452.

32. Sustainable Development Goals. Available online: https://www.un.org/sustainabledevelopment/zh/ (accessed on 5 March 2017).

33. Lin, C.H. Innovational Model of Fashion Design from the Viewpoint of Aesthetic Economic. Taiwan Text. Res. J. 2009, 19, 27-41.

34. Pine, B.J.; Pine, J., II; Gilmore, J.H. The Experience Economy: Work Is Theater E Every Business a Stage, 1st ed.; Harvard Business School Press: Boston, MA, USA, 1999; ISBN 0875848192.

35. Mircea, E.; Wang, H.K. The Scared and The Profane, 1st ed.; Huaxia Publishing House: Beijing, China, 2002; ISBN 7508028344.

36. Ysseldyke, J.; Krentz, J.; Elliott, J.; Thurlow, M.L.; Erickson, R.; Moore, M.L. NCEO Framework for Educational Accountability; University of Minnesota, National Center on Educational Outcomes: Minneapolis, MN, USA, 1998.

37. Sun, C.L. Construction and Application of an Indicator SYSTEM for Compulsory Education. Ph.D. Thesis, National Chengchi University, Taipei, Taiwan, 1998, unpublished.

38. Nightingale, P.; Ibbetson, A.; Pugh, R. An evaluation of the impact of a multidisciplinary educational event focusing on teamwork and leadership skills in primary care. Educ. Prim. Care 2003, 14, 345-355.

39. Sanders, J.R. Program/project evaluation. In International Handbook of Educational Evaluation; Kellaghan, T., Stufflebeam, D.L., Wingate, L.A., Eds.; Kluwer Academic: Norwell, MA, USA, 2003; pp. 697-700.

40. Tyler, R.W. Basic Principles of Curriculum and Instruction, 1st ed.; Revised Edition; University of Chicago Press: Chicago, IL, USA, 2013; ISBN 022608650X.

41. House, E.R. Professional Evaluation: Social Impact and Political Consequences, 1st ed.; Sage Pub.: Newbury Park, CA, USA, 1993; ISBN 0803949960.

42. Nachmias, D.; Nachmias, C. Public Policy Evaluation: Approaches and Methods; St. Martin's: New York, NY, USA, 1979.

43. Evert, V. Public Policy and Program Evaluation, 1st ed.; Routledge Press: New York, NY, USA, 2013; ISBN 0765806878.

44. CRIHAP. Available online: http://www.crihap.cn/2014-07/02/content_17638153.htm (accessed on 13 February 2017).

45. United Nations Educational, Scientific and Cultural Organization. Available online: http://portal.unesco.org/en /ev.php-URL_ID=31038\&URL_DO=DO_TOPIC\&URL_SECTION=201.html (accessed on 13 February 2017).

46. UNESCO. Intangible Cultural Heritage. Available online: https://ich.unesco.org/en/decisions/10.COM/1 5.A (accessed on 13 February 2017). 
47. Shen, Z.Z. Chinese Farming Culture, 1st ed.; China Agricultural Press: Beijing, China, 2012; ISBN 9787109137363.

48. Qiu, B.J. Chinese Twenty-Four Solar Terms, 1st ed.; Chemical Industry Press: Beijing, China, 2018; ISBN 9787122311603.

49. Meltsner, A.J. Policy Analysis in the Bureaucracy, 1st ed.; University of California Press: Berkeley, CA, USA, 1976; ASIN B01K3NJNWO.

50. Weimer, D.L.; Vining, A.R. Policy Analysis: Concepts and Practice, 2nd ed.; Prentice Hall: Upper Saddle River, NJ, USA, 1992; ISBN 9780136831457.

51. Wang, K.M.; Wu, H.T.; Wu, M.L. The reconstruction of evaluation indicators for elementary schools in Kaohsiung city. J. Educ. Admin. Eval. 2008, 5, 75-106.

52. Zheng, C.H. The Research of Constructing the Evaluation Indicator of Elementary Schools. Master's Thesis, National Sun Yat-sen University, Kaohsiung, Taiwan, 2005, unpublished.

53. Li, J.C. Practice and Application of SPSS Statistical Analysis, 1st ed.; Ch Wa Books: Taipei, Taiwan, 2007; ISBN 9789571148427.

54. Chiou, H.J. Quantitative Research and Statistical Analysis in Social E Behavioral Sciences, 3rd ed.; Wu Nan Books: Taipei, Taiwan, 2010; ISBN 9789571188911.

55. Nunnally, J. Psychometric Theory, 3rd ed.; McGraw-Hill: New York, NY, USA, 1994; ISBN 007047849X.

56. Lee, Y.C.; Ho, M.C. A Study on the Weighting of Indicators for Image Design. J. Des. 2011, 16, 41-64.

(C) 2018 by the authors. Licensee MDPI, Basel, Switzerland. This article is an open access article distributed under the terms and conditions of the Creative Commons Attribution (CC BY) license (http://creativecommons.org/licenses/by/4.0/). 